\title{
Prevalence of Snoring and Obstructive Sleep Apnea Syndrome among Nurses and Resident Doctors Working in a University Hospital
}

\author{
Ömer Soylu', Fatma Erboy², Tacettin Örnek2, Figen Atalay², Bülent Altnnsoy², \\ Hakan Tanriverdi², Frrat Uygur', Meltem Tor ${ }^{2}$ \\ ${ }^{1}$ Clinic of Respirataory Medicine, Uzunmehmet Pulmonary and Occupational Diseases Hospital, Zonguldak, Turkey \\ ${ }^{2}$ Department of Respiratory Medicine, Bülent Ecevit University Faculty of Medicine, Zonguldak, Turkey
}

\begin{abstract}
Objective: Sleep disorders are important public health issues that decrease the individuals' quality of life by affecting their productivity and performance in a negative way. The frequency of sleep disorders among people who work shifts with irregular sleep patterns is apparent. For healthcare providers, most of whom work shifts, the available data related to obstructive sleep apnea syndrome (OSAS) are insufficient. Also, this is the first study that has been conducted using an all-night polysomnography (PSG) for health staff in our country. In our study, we aimed to investigate the prevalence of snoring and OSAS among the nurses and resident doctors working at our hospital.

Methods: Face-to-face interviews were performed with all nurses and resident doctors who worked at our hospital and agreed to participate in our study. All-night PSG examination was recommended to participants with concurrent witnessed apnea and/or excessive daytime sleepiness (EDS) with snoring. The frequency of OSAS was evaluated in cases exposed to polysomnography, and those with and without OSAS were compared in terms of shift rates.

Results: The study included 257 participants. Of these, 63\% were nurses and 37\% were resident doctors; overall, $34.2 \%$ of the cases were male. The mean age was $28.8 \pm 3.7$ (19-39) years and the mean body mass index was $24.03 \pm 3.85 \mathrm{~kg} / \mathrm{m}^{2}$. Among the participants, the mean number of monthly night shifts was $7.6 \pm 3.8$. Also, $28.8 \%$ of the participants $(n=74)$ experienced snoring, $2.7 \%(n=7)$ had witnessed apnea, and $7.8 \%(n=20)$ had EDS (Epworth sleepiness scale $\geq 11)$. Four (1.6\%) of the 20 participants who were proposed to undergo PSG refused this examination. Sixteen cases were exposed to PSG (6.2\%). According to the PSG results, the prevalence of OSAS was $4.7 \%$ among all healthcare providers and 5.1\% among the health staff working shifts. Of the cases with OSAS, 91.7\% (11/12) were working shifts while 83.3\% (204/245) of those without OSAS were working shifts $(\mathrm{p}=0.697)$. All of the cases diagnosed with OSAS were male, but $31 \%$ of the cases without OSAS were male $(p<0.001)$.
\end{abstract}

Conclusion: For those healthcare providers who are engaged in duties requiring significant amounts of attention and concentration, the symptoms related to sleep disorders should be questioned and diagnostic evaluation and treatment should be performed for suspected cases.

Keywords: Health care providers, OSAS, sleep disorders, shift work

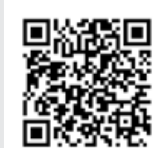

Received Date: 03.03 .2014 Accepted Date: 26.05 .2014

Address for correspondence

Tacettin Örnek, Department of Respiratory Medicine, Bülent Ecevit University Faculty of

Medicine, Zonguldak, Turkey

E-mail: tacettinornek@yahoo.com

(C) Copyright 2014 Turkish Respiratory Society (TRS) Eurasian J Pulmonol 2014

DOI: 10.5152/ejp.2014.68984

- Available online at www.eurasianjpulmonol.com

\section{INTRODUCTION}

Obstructive Sleep Apnea Syndrome (OSAS) is characterised by the episodes of complete or partial upper respiratory airway obstruction recurring during sleep and often a reduction in blood oxygen saturation (1). The gold standard diagnostic method for this syndrome is polysomnography (PSG).

Although PSG is the final diagnostic method for OSAS, most OSAS prevalence studies have been conducted based on symptoms rather than PSG results. However, there are some studies in which symptoms and PSG test results have been evaluated together in order to estimate the prevalence of OSAS. In a widespread prevalence study in which the criteria for the diagnosis of OSAS were the presence of excessive daytime sleepiness (EDS) and apnea-hypopnea index (AHI) of $\geq 5$, the frequency of OSAS was found to be $4 \%$ in males and $2 \%$ in females (2).

Sleep disorders are more common among people working shifts with irregular sleep patterns. When insufficient sleep coexists with shift work, an increased tendency to sleep poses a more serious problem (3). An excessive tendency to sleep during work is observed 2-5 times more often in shift workers than in daytime workers. Irregular sleep patterns of shift workers and the associated infirmity and excessive tendency to sleep in the daytime can cause serious job accidents. Neurocognitive functions 
such as attention, concentration ability and memory are considerably deteriorated in OSAS (4).

For health staff, the great majority of whom work shifts, data related to the prevalence of OSAS are insufficient. A few studies about OSAS in health staff are based on data obtained from questionnaires.

In this study, it was aimed to investigate the prevalence of snoring and OSAS among nurses and the resident doctors, most of whom worked shifts in our hospital.

\section{METHODS}

The face-to-face interview method was performed with nurses and resident doctors working in a university hospital and who agreed to participate in the study. In total, 257 health staff completed a questionnaire modified according to the Berlin Questionnaire and Pittsburgh Sleep Quality Index (PSQI) $(5,6)$. This questionnaire included 76 items questioning the participants' sleep duration, sleep patterns, sleep quality, habitual sleep efficiency, symptoms related to sleep disorders (snoring, witnessed apnea, EDS, dyspnea at sleep, personality and behaviour disorders, anxiety and depression, job accident, leg restlessness) and the features and severity of these symptoms, additional diseases, habits, socio-demographic features, working in shifts and shifting rules. The Epworth Sleepiness Scale (ESS) was used to reveal excessive daytime sleepiness. Moreover, the age, gender, body mass index (BMI) and branches of the health staff participating in the questionnaire were recorded (7).

After evaluation of the questionnaires, PSG examination was recommended to the participants who had concurrent apnea and/or EDS with snoring. Of the 20 participants who were recommended to undergo polysomnography, 16 accepted a PSG examination.

All-night PSG examination was performed with a 55-channel Alice 5 computed system (Respironics; Philips, Illinois, USA). The channels used in the study were: 6 channels electroencephalography (EEG), 2 channels electrooculogram (EOG), 1 channel nasal pressure sensor, 1 channel thermistor, 1 channel microphone, 1 channel chest effort, 1 channel abdominal effort, 2 channels foot electromyography (EMG), 1 channel pulse oximeter sensor, 2 channels chin EMG, 4 channels electrocardiography (EKG) and 1 channel body position. Chest and abdominal efforts were measured with the elastomeric plethysmography method. Polysomnography scoring and OSAS definition were performed according to the "American Academy of Sleep Medicine" criteria (8). Apnea was defined as a $90 \%$ or greater reduction in the airflow measured with thermistor lasting for at least 10 seconds. Moreover, another essential condition for the definition of apnea was meeting the amplitude criterion for $90 \%$ or more of the time. Two different criteria were used for hypopnea and the presence of any of these criteria was considered hypopnea. The first criterion was defined by the presence of a $30 \%$ or greater decrease from the basal, which lasted for at least 10 seconds, in the nasal pressure signal together with $4 \%$ or greater desaturation. The second criterion was defined by the presence of a $50 \%$ or greater decrease from the basal, which lasted for at least 10 seconds, in the nasal pressure signal together with $3 \%$ or greater desaturation. Moreover, in both criteria defined for the diagnosis of hypopnea, another requirement was to meet the amplitude criterion $90 \%$ of the time or more. The total number of apnea and hypopnea episodes per hour was defined according to the Apnea Hypopnea Index (AHI).
Working in shifts was defined as working for 16 hours from 04.00 p.m. to 08.00 a.m. or for 24 hours from 08.00 a.m. to 08.00 a.m. on the following day.

All of the participants were given detailed information about the study and written informed consent forms were obtained from them. The study protocol was approved by the ethics committee of the university in the meeting numbered 2012/20 on October 16, 2012.

\section{Statistical Analyses}

Statistical analysis was performed using SPSS 18.0 for Windows (Statistical Package for the Social Sciences). Descriptive statistics were expressed as mean \pm standard deviation or median (minimum-maximum) for numeric variables and as number and percentage for categorical variables. Chi-square and Fisher's Exact Chi-square tests were employed for comparing two groups in terms of categorical variables. Also, the Mann-Whitney $U$ test was used to compare two groups for numerical variables. The value of $p<0.05$ was considered significant.

\section{RESULTS}

Two hundred and fifty seven participants were included in the study. Of the participants, $63 \%$ were nurses and $37 \%$ were resident doctors. The mean age of the cases was $28.8 \pm 3.7$ (19-39) years, the mean body mass index was $24.03 \pm 3.85 \mathrm{~kg} / \mathrm{m}^{2}$, and $34.2 \%$ of them were male (Table 1).

Four (1.6\%) of the 20 participants who were proposed to undergo PSG refused examination, so only 16 cases (6.2\%) underwent PSG. According to PSG results, the prevalence of OSAS in the cases participated in the study was $4.7 \%(12 / 257)$. The mean AHI was found to be $8.07 \pm 4.54$ for the 12 patients diagnosed with obstructive sleep apnea syndrome. One patient $(\mathrm{AHI}=22)$ was found to have moderate and the other 11 patients mild OSAS. In comparison of the participants with and without OSAS, the values of BMI were significantly higher in the cases with OSAS.

Of the cases, $28.8 \%(n=74)$ had snoring, $2.7 \%(n=7)$ had witnessed apnea (Table 2$)$, and $7.8 \%(n=20)$ had EDS (ESS $\geq 11)$. OSAS was detected through PSG in only 3 of 20 participants with EDS (15\%). Eleven of the 17 patients with an ESS value of $\geq 11$ and without OSAS

Table 1. Demographic features of the patients

\begin{tabular}{|l|c|}
\hline Age- year (interval) & $28.78 \pm 3.74(19-39)$ \\
Body mass index- $\mathrm{kg} / \mathrm{m}^{2}$ & $24.03 \pm 3.85$ \\
Gender & \\
$\quad$ Male- $\mathrm{n}(\%)$ & $88(34.2)$ \\
Female- $\mathrm{n}(\%)$ & $169(65.8)$ \\
Occupation & $95(37)$ \\
Doctor- $\mathrm{n}(\%)$ & $162(63)$ \\
Nurse- $\mathrm{n}(\%)$ & \\
Smoking & $156(60.7)$ \\
Never smoked- $\mathrm{n}(\%)$ & $73(28.4)$ \\
Active smoker- $\mathrm{n}(\%)$ & $28(10.9)$ \\
Smoked but quitted- $\mathrm{n}(\%)$ &
\end{tabular}


Table 2. Distribution of the symptoms related to sleep disorders

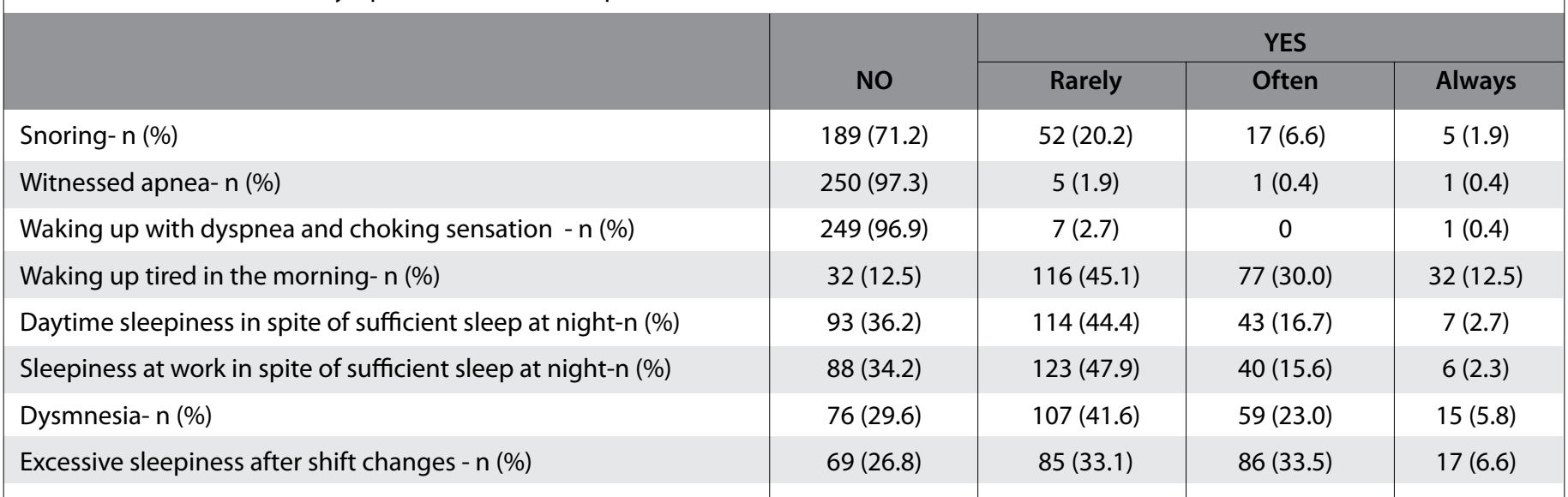

Table 3. Epworth sleepiness scale analysis for the individuals involved in the study

\begin{tabular}{|c|c|c|c|c|}
\hline & $\begin{array}{l}\text { I never feel } \\
\text { sleepy }\end{array}$ & $\begin{array}{l}\text { I rarely feel } \\
\text { sleepy }\end{array}$ & $\begin{array}{l}\text { I often feel } \\
\text { sleepy }\end{array}$ & $\begin{array}{l}\text { I always feel } \\
\text { sleepy }\end{array}$ \\
\hline While reading newspaper $-\mathrm{n}(\%)$ & $90(35.1)$ & $124(48.2)$ & $37(14.4)$ & $6(2.3)$ \\
\hline While watching TV- n (\%) & $72(28.0)$ & $128(49.8)$ & $47(18.3)$ & $10(3.9)$ \\
\hline While sitting- $\mathrm{n}(\%)$ & $168(65.4)$ & $65(25.3)$ & $19(7.4)$ & $5(1.9)$ \\
\hline While traveling- $\mathrm{n}(\%)$ & $88(34.2)$ & $96(37.4)$ & $51(19.8)$ & $22(8.6)$ \\
\hline While speaking- $\mathrm{n}(\%)$ & $235(91.4)$ & $21(8.2)$ & $1(0.49)$ & 0 \\
\hline After meals- $\mathrm{n}(\%)$ & $149(58.0)$ & $80(31.1)$ & $27(10.5)$ & $1(0.4)$ \\
\hline While waiting in traffic- $\mathrm{n}(\%)$ & $239(93.0)$ & $16(6.2)$ & $1(0.4)$ & $1(0.4)$ \\
\hline
\end{tabular}

were working in shifts. The coexistence of snoring, witnessed apnea and EDS was found in $1.5 \%$ of the cases $(n=4)$. ESS values of the participants are shown in Table 3. No case with suspected upper airway resistance syndrome and narcolepsy was observed.

Among the participants, the mean of monthly night shifts was 7.6 \pm 3.8 . Two hundred and fifteen (83.7\%) of the cases worked shifts. The prevalence of OSAS in shift workers was $5.1 \%$. Of the cases with obstructive sleep apnea syndrome, 91.7\% (11/12) were working shifts, but $83.3 \%$ (204/245) of those without OSAS were working in shifts ( $p=0.697$ ). All cases diagnosed with OSAS were male while $31 \%$ of the cases without OSAS were male $(p<0.001)$. BMI values of the participants with OSAS $\left(31.37 \pm 4.75 \mathrm{~kg} / \mathrm{m}^{2}\right)$ were found to be higher than those of the participants without OSAS $\left(23.67 \pm 3.42 \mathrm{~kg} / \mathrm{m}^{2}\right)$ $(p<0.001)$ (Table 4).

\section{DISCUSSION}

In our study, the prevalence of OSAS was found to be $4.7 \%$ among health staff and $5.1 \%$ among those health staff working shifts. Of the participants, $28.8 \%$ had snoring, $2.7 \%$ had witnessed apnea and $7.8 \%$ had EDS. There was no significant difference between cases with OSAS and those without in terms of shift frequency.

Obstructive sleep apnea syndrome is observed more commonly in middle-aged individuals and its prevalence among adults is estimated to be about $2-4 \%$ (9). No published study showing the prevalence of OSAS through PSG is available in our country. Data regarding the prevalence of OSAS among health staff most of whom work in shifts are insufficient. A few studies about OSAS among health staff are based on data obtained from questionnaires.

The studies conducted with individuals working in shifts have found rates of OSAS to be different from each other. This difference is thought to be caused by variations in risk factors such as age, gender and BMI. In individuals with irregular sleep patterns and decreased daytime adaptation, an increase is seen in daytime sleepiness and in concentration loss. Garbarino et al. (10) found that the rate of sleep disorders was $35.7 \%$ for police officers working in shifts and $26.3 \%$ for those only working during the daytime. Furthermore, EDS was detected in bus drivers working shifts (11). In a study conducted by Akkoyunlu et al. (12) in our clinic, the all-night PSG test was performed for 241 long-distance drivers and the prevalence of OSAS was found to be $14.1 \%$. In another study involving 410 long-distance bus drivers in Hong Kong, 17 people were selected from each shift and were exposed to PSG. According to the polysomnography results, 31 (7.5\%) individuals with the value of $\mathrm{AHI} \geq 5$ were diagnosed with OSAS (13). A similar study conducted in Spain revealed the prevalence of OSAS to be $8.6 \%$ for 163 long-distance transport drivers (14).

In our study, the prevalence of OSAS for health staff working shifts was $5.1 \%$. This ratio is close to the prevalence of OSAS for the whole population but lower than the prevalence of OSAS among many 
Table 4. Comparison of the cases with and without OSAS in terms of the factors including age, body mass index, gender, shift working and smoking

\begin{tabular}{|c|c|c|c|}
\hline Variable & $\begin{array}{l}\text { Without OSAS } \\
\quad(n=245)\end{array}$ & $\begin{array}{l}\text { With OSAS } \\
\qquad(n=12)\end{array}$ & $p$ \\
\hline Age & $28.1 \pm 3.4$ & $30.1 \pm 2.5$ & 0.057 \\
\hline Body mass index- $\mathrm{kg} / \mathrm{m}^{2}$ & $23.67 \pm 3.42$ & $31.37 \pm 4.75$ & $<0.001$ \\
\hline \multicolumn{4}{|l|}{ Gender- n (\%) } \\
\hline Male & $76(31)$ & $12(100)$ & $<0.001$ \\
\hline Female & $169(69)$ & 0 & \\
\hline \multicolumn{4}{|l|}{ Shift- n (\%) } \\
\hline Shift working & $204(83.3)$ & $11(91.7)$ & 0.697 \\
\hline Not shift working & $41(16.7)$ & $1(8.3)$ & \\
\hline History of smoking- $\mathrm{n}(\%)$ & $94(38.4)$ & $7(58.3)$ & 0.395 \\
\hline
\end{tabular}

groups working in shifts. The fact that the health workers in our study were younger than those in other occupational groups working shifts may explain the reason for the lower OSAS ratios to a certain degree.

Doğan et al. (15) conducted a survey study with 1202 health staff consisting of physicians, nurses, technicians and lab workers in Sivas and found the rate of snoring to be $22 \%$, the rate of witnessed apnea to be $4.4 \%$ and the rate of EDS to be $28.1 \%$. All three of these symptoms were present in $1.8 \%$ of participants. The presence of snoring, witnessed apnea and three symptoms together in our study was similar to that in the study conducted in Sivas. The rate of EDS in the study in Sivas was found to be quite high compared to our study. However, the ESS value defined as EDS was not stated in that study. In a study performed in another health centre, Sönmez et al. (16) reported the prevalence of snoring to be $35.9 \%$, the prevalence of habitual snoring to be $5.4 \%$ and the prevalence of EDS to be $15.4 \%$ for nurses working in shifts. Similar results were also obtained in our study.

The Epworth Sleepiness Scale is a subjective measure evaluating sleepiness. There are many causes of hypersomnia, but the most common is sleep breathing disorders. In a study conducted on taxi drivers, the frequency of individuals with an ESS score over 10 was found to be $23.7 \%$. Also, the frequency of accident risk for those with EDS was reported to be $67.8 \%$ in the same study (17). In our study, 17 of the 20 individuals with the value of EUS $\geq 11$ did not have OSAS. It was thought that higher ESS values could be explained by shift working since 11 of these 17 individuals also worked at night. Many diseases and conditions (inadequate sleep, drugs, depression, comorbid diseases, psychiatric conditions, other sleep disorders except OSAS) besides obstructive sleep apnea syndrome can lead to EDS (18). We suggest that high ESS values of 6 individuals working daytime might be the result of another condition rather than OSAS.

A relationship was demonstrated between EDS and job accidents. Suzuki et al. (19) found the rate of daytime sleepiness to be $26 \%$ for nurses working shifts. They suggested that the number of job accidents (malpractice of drugs, selection of wrong surgical instruments or needle stick injury) increased significantly among nurses with daytime sleepiness.
Linberg et al. (20) revealed a relationship between EDS and snoring and job accidents in a study conducted using 2874 participants. In their study, it was demonstrated that shift working was an independent risk factor for job accidents and found that the risk of job accidents within 10 years for workers with both symptoms (EDS and snoring) increased 2.2-fold. Gold et al. (21) conducted a study with 635 nurses and found that the possibility of job accident and making a mistake due to sleeplessness was 2-fold higher for the nurses working shifts compared to daytime nurses. Moreover, Perez et al. (22) reported that snoring and ESS score positively correlated with job accidents independently.

In the study by Komada et al. (23), it was suggested that the number of motor vehicle accidents was decreased through "Continuous Positive Airway Pressure (CPAP)" treatment. It was also stated that drivers with OSAS and severe sleep disorder (EUS $\geq 11$ and $\mathrm{AHI} \geq 40$ ) had to be diagnosed early and treated, and that motor vehicle accidents could be avoided via appropriate CPAP treatment.

Kara et al. (24) stated in their study that the rate of snoring increased by 3.9 times in individuals older than 40 years. In our study, increasing risk for advanced age was not mentioned because the participants were all aged between 19 and 39 years.

In previous studies, whether obesity increases the tendency to OSAS has been explored. It was reported that the OSAS risk increased 8-12 times in individuals with $\mathrm{BMI}>29$ and was higher in individuals with upper-body obesity and in the morbidly obese patients with $\mathrm{BMI}>40$ (25). In our study, when the individuals with OSAS were compared to those without, it was found that BMI values were significantly higher for participants with OSAS. In a study of BMI conducted with young adults in our country, the mean BMI was found to be $22.4 \pm 3.03$ in males and 20.76 \pm 2.54 in females (26). Considering age, the mean values for BMI in our study were similar to those in general society.

The prevalence of OSAS was reported to be lower among females and the young population $(27,28)$. In our study, it is believed that the higher number of female participants and the fact that the study population consisted of young people might have contributed to the lower than expected prevalence of OSAS. Another reason for the lower prevalence of OSAS in shift workers than in society as a whole might be that the individuals working actively at these roles have the potential to be healthier.

Our study has some limitations, although it is important for demonstrating the prevalence of OSAS through PSG among health staff. Those health staff working in shifts and working daytime could not be compared because there were fewer individuals working in the daytime. Moreover, the health staff involved in our study were very young (28.78 \pm 3.74 years), which might pose a problem for comparison of the data obtained by other studies conducted with other shift working populations with our data. We suggest that the results of the all-night PSG test performed for some selected specific individuals, rather than all individuals in the study group or those individuals with at least one of three major symptoms, show the prevalence of OSAS to be lower than it actually is.

\section{CONCLUSION}

Consequently, OSAS is an important health issue for health staff, a great majority of whom work in shifts. In cases with obstructive sleep 
apnea syndrome, EDS and attention deficit are detected. Therefore, the symptoms related to sleep disorders should be questioned in shift workers and the necessary examinations and treatments should be performed for those with sleep disorders. Moreover, the individuals with OSAS should be charged with duties requiring less attention.

Ethics Committee Approval: Ethics committee approval was received for this study from the ethics committee of Bülent Ecevit University Ethical Committee of Clinical Trials.

Informed Consent: Written informed consent was obtained from patients who participated in this study.

Peer-review: Externally peer-reviewed.

Author Contributions: Concept - Ö.S., F.E.; Design - Ö.S., F.E.; Supervision - B.A., F.U.; Resource - Ö.S., T.Ö.; Materials - H.T., F.U.; Data Collection\&/or Processing - B.A., H.T.; Analysis\&/or Interpretation - F.A., M.T.; Literature Search - Ö.S., T.Ö.; Writing - Ö.S., T.Ö.; Critical Reviews - F.A., M.T.

Conflict of Interest: No conflict of interest was declared by the authors.

Financial Disclosure: The authors declared that this study has received no financial support.

\section{REFERENCES}

1. Park JG, Ramar K, Olson EJ. Updates on definition, consequences, and management of obstructive sleep apnea. Mayo Clin Proc 2011; 86: 54954.

2. Young T, Palta M, Dempsey J, Skatrud J, Weber S, Badr S. The occurrence of sleep-disordered breathing among middle-aged adults. N Engl J Med 1993; 328: 1230-5.

3. Karadağ $M$, Ursavaş A. Sleep Study in the World and Turkey. Akciğer Arşivi 2007; 8: 62-64.

4. Dement W. History of sleep physiology and medicine. In: Kryger M, Roth T, Dement W, editors. Principles and practice of sleep medicine. Philadelphia: W.B. Saunders Company 2005: 1-12.

5. Netzer NC, Stoohs RA, Netzer CM, Clark K, Strohl KP. Using the Berlin questionnaire to identify patients at risk for the sleep apnea syndrome. Ann Intern Med 1999; 131:485-91.

6. Buysse DJ, Reynolds CF 3rd, Monk TH, Berman SR, Kupfer DJ. The Pittsburgh Sleep Quality Index: A new instrument for psychiatric practice and research. Psychiatry Res 1989; 28: 193-213.

7. Johns M. A new method for measuring daytime sleepiness: the Epworth sleepiness scale. Sleep 1991; 14: 540-5.

8. Iber C, Ancoli-Israel S, Chesson A, Quan SF, American Academy of Sleep Medicine. The AASM manual for the scoring of sleep and associated events: rules, terminology and technical specifications. American Academy of Sleep Medicine: Westchester, IL, 2007.

9. Azagra-Calero E, Espinar-Escalona E, Barrera-Mora JM, Llamas-Carreras $J M$, Solano-Reina E. Obstructive sleep apnea syndrome (OSAS). Review of the literature. Med Oral Patol Oral Cir Bucal 2012; 17: e925-9.

10. Garbarino S, De Carli F, Nobili L, Mascialino B, Squarcia S, Penco MA, et al. Sleepiness and sleep disorders in shift workers: a study on a group of italian police officers. Sleep 2002; 25: 648-53.
11. Hui DS, Chan JK, Ko FW, Choy DK, LiTS, Chan AT, et al. Prevalence of snoring and sleep-disordered breathing in a group of commercial bus drivers in Hong Kong. Intern Med J 2002; 32: 149-57.

12. Akkoyunlu ME, Altın R, Kart L, Atalay F, OrnekT, Bayram M, et al. Investigation of obstructive sleep apnea syndrome prevalence among long-distance drivers from Zonguldak, Turkey. Multidiscip Respir Med 2013; 8: 10.

13. Hui DS, Ko FW, Chan JK, To KW, Fok JP, Ngai JC, et al. Sleep disordered breathing and continuous positive airway pressure compliance in a group of commercial bus drivers in Hong Kong. Respirology 2006: 11; 723-30.

14. Diaz J, Guallar J, Arnedo A, Oliva S, Gala J. (Prevalence of sleep apnea-hypopnea syndrome among long-haul professional drivers). Arch Bronconeumol 2001: 37; 471-6.

15. Doğan OT, Berk S, Ozşahin SL, Arslan S, Düzenli H, Akkurt I. Symptom prevalence of obstructive sleep apnea-hypopnea syndrome in healthcare providers in central Sivas. Tuberk Toraks 2008; 56: 405-13.

16. Sönmez S, Ursavaş A, Uzaslan E, Karadağ M, Ege E. Sleep Disorders and occupational accident in shift work nurses. Turk Thorac J 2010; 11: 105-8.

17. Gülbay BE, Acican T, Doğan R, Baççioğlu A, Güllü E, Karadağ G. The evaluation of excessive daytime sleepiness in taxi drivers. Tuberk Toraks 2003; 51: 385-9.

18. Ruggles K, Hausman N. Evaluation of excessive daytime sleepiness. WMJ. 2003; 102: 21-4.

19. Suzuki K, Ohida T, Kaneita Y, Yokoyama E, Uchiyama M. Daytime sleepiness, sleep habits and occupational accidents among hospital nurses. J Adv Nurs 2005; 52: 445-53.

20. Lindberg E, Carter N, Gislason T, Janson C. Role of snoring and daytime sleepiness in occupational accidents. Am J Respir Crit Care Med 2001; 164: 2031-5.

21. Gold DR, Rogacz S, Bock N, Tosteson TD, Baum TM, Speizer FE, et al. Rotating shift work, sleep, and accidents related to sleepiness in hospital nurses. Am J Public Health 1992: 82; 1011-4.

22. Pérez-Chada D, Videla AJ, O'Flaherty ME, Palermo P, Meoni J, Sarchi MI, et al. Sleep habits and accident risk among truck drivers: a cross-sectional study in Argentina. Sleep 2005; 28: 1103-8.

23. Komada $Y$, Nishida $Y$, Namba K, Abe T, Tsuiki S, Inoue Y. Elevated risk of motor vehicle accident for male drivers with obstructive sleep apnea syndrome in the Tokyo metropolitan area. Tohoku J Exp Med 2009; 219: 11-6.

24. Kara CO, Zencir M, Topuz B, Ardiç N, Kocagözoğlu B. The prevalence of snoring in adult population. Kulak Burun Bogaz Ihtis Derg 2005; 14: 18 24.

25. Chesson AL Jr, Ferber RA, Fry JM, Grigg-Damberger M, Hartse KM, Hurwitz TD, et al. The indications for polysomnography and related procedures. Sleep 1997; 20: 423-87.

26. Ergün A, Erten SF. Body Mass Index and Waist Circumference in estimation of Obesity in Students. Ankara Üniversitesi Tıp Fakültesi Mecmuası 2004; 57: 57-61.

27. Punjabi NM. The epidemiology of adult obstructive sleep apnea. Proc Am Thorac Soc 2008; 5: 136-43.

28. McNicholas WT, Bonsignore MR. Sleep apneoa. European Respiratory Monograph 2010; 50; 51-68. 